\title{
Distributive Justice and the Problem of Friendship
}

\section{Chiara Cordelli}

University of Exeter

Friendship distributes critical benefits across society and does so unequally. Income, levels of education and health vary dramatically according to the quality of individuals' friendships. Further, friendships shape the motivations and aspirations of their participants. In light of these facts, this article questions whether and how egalitarian requirements should apply to personal friendship. I first show that existing theories of distributive justice, whether they are 'outcomes centred' or 'institutionalist', have reasons to consider personal friendship as a direct subject of justice. However, both fail to provide reasonable guidelines for how to apply the requirements of justice to friendship. I thus argue that principles of justice, in particular fair equality of opportunity, ought to assess and govern that part of the social structure that controls the production and distribution of friendship bonds across society. I theorise a 'relational distributive structure', mainly constituted by civil society associations, as the appropriate subject of justice.

Keywords: friendship; distributive justice; personal prerogative; civil society; egalitarianism

People with many friends tend to be healthier and to live longer (Berkman, 1995). Income, wealth and levels of education vary dramatically according to the quality of individuals' friendships (Lin, 2001). Adolescents' aspirations are profoundly shaped by their friends (Buss, 2000). Nowadays, with many individuals living outside the context of nuclear families, reliance upon friends often also becomes a substitute for family members (Rosenbury, 2007). Personal friendship, in all of these ways, plays an increasingly important role in people's lives and their societies.

Despite the ever-pervasive effects of friendship bonds on individuals' lives, and despite politics scholars' renewed interest in friendship (see Devere and Smith, 2010), theorists of distributive justice have paid little attention to personal friendship. ${ }^{1}$ Friendship is treated either as being outside the direct purview of distributive justice altogether, or as part of those personal pursuits that should be exempted from requirements of justice through a personal prerogative (Cohen, 2008, pp. 10-1, pp. 61-3). Debates about the scope of distributive justice within the 'private' sphere remain confined to the family and the market.

After clarifying what I mean by friendship and which relationships fall within this category, I shall investigate whether and how egalitarian principles of distributive justice apply to friendship. I will first argue that egalitarians (e.g. Cohen, 2008) who are primarily concerned with the distributive outcomes of personal choices and social structures alike hereafter 'outcomes-centred egalitarians' - cannot easily exempt friendship choices from the purview of egalitarian justice. How we choose our friends and distribute benefits to them upsets the overall distribution of benefits and burdens in society. Likewise, theorists of justice (e.g. Rawls, 1971) who primarily focus on the justice of social institutions - 
hereafter 'institutionalists' - have reasons to extend the purview of justice directly to the practice of friendship. This practice, I argue, shares with the institution of the family several of those very features that make the latter a legitimate subject of justice (Okin, 1989).

However, both strands of theory fail to provide adequate directives for how principles of justice should govern friendship. Outcomes-centred egalitarians would seem to be committed to applying egalitarian requirements directly to friendship choices. Individuals would be required to pick their friends, and to distribute the benefits of friendship, according to an egalitarian ethos. Call this mode of application choice extensionism. This, I will show, would have the undesirable result of compromising the very possibility of friendship. Attempts to correct choice extensionism by allowing a 'personal prerogative' for friendship choices, I will argue, also fail appropriately to reconcile justice and friendship. Choice extensionism is not the appropriate way to extend principles of justice to friendship.

Institutionalists may attempt to apply principles of justice to the public institution of friendship, and only indirectly to the choices made within it. Call this mode of application legal extensionism. However, given the absence of a legal system of rules to frame friendship, it is unclear how principles of justice could apply to friendship in this way. Also, the argument that a public institution of friendship should be instituted may be refuted on moral grounds, or so I will argue. Legal extensionism must be ruled out as well.

I will thus argue that, instead of directly governing friendship choices or regulating the institution of friendship, principles of social justice should rather assess and govern the set of social organisations - what I call the 'relational distributive structure' - that fundamentally shape the production and distribution of friendships. This normative solution to the problem of friendship defends personal friendship from liberty-undermining intrusions, but also has important implications for social and public policy. I conclude by exploring how governments might shape those relational contexts in which friendships form and reproduce.

\section{Defining Friendship}

Let me begin by clarifying the kinds of friendship that I am concerned with, and how they differ from other relationships. Friendship is after all a notoriously vague term whose meaning has radically changed over time (Allan, 1996). Social scientists identify many different forms of friendship (see Spencer and Pahl, 2006, ch. 3). In this article, I will call 'friendships' one particular set of interpersonal relationships, which are voluntary and, to some degree, affective, as well as non-instrumental. Framed by a distinctively loose institutional structure, they are further characterised by 'rough reciprocity' as their central norm of exchange.

Friendships, unlike relationships of kinship, are voluntary in that we are not born into them and (in a sense to be qualified) we 'choose' our friends. Yet unlike other voluntary relationships - for example marriage and many market relationships - friendships are non-contractual. ${ }^{2}$ They develop slowly and it is only through the sharing of experiences, as well as the roughly reciprocal - balanced but not necessarily equal - and trust-infused exchange of material and immaterial goods (e.g. practical and emotional support) over time that we express a commitment to be someone's friend. 
Further, unlike relationships based on impersonal benevolence and civic friendships, the friendships I am concerned with are affective and particularistic relationships. Although friendships can certainly exhibit very different degrees of affection and intimacy, they require, at least to some degree, the presence of an emotional bond. They cannot therefore come into existence in the complete absence of those repeated interactions through which attachment is generated. Further, in order for an action to count as an act of friendship, friends must take into account the particular identity of their friends qua friends in deciding on right action call this condition friendship particularism (Hooker and Little, 2000). Therefore, strangers do not count as friends in my account, even if they are committed fellow citizens.

However, unlike other affective relationships such as families, friendships are not sensu stricto 'institutions'. Although culturally constrained, friendships are not defined by a clear framework of rules and they lack a clearly spelled out social purpose (see Blatterer, 2013). This unstructured and flexible nature is what makes friendship, as I hope to illustrate, particularly vexing for egalitarian justice.

Finally, although friendships can be (and almost always are) grounded on a mix of different motives (affection, utility and pleasure), purely instrumental bonds are not included in my account of friendship, unless they also exhibit some degree of noninstrumental concern. By this I mean that friends must at least sometimes be prepared to act for their friends' own sake, as their final goal, rather than as a means towards some end (Blum, 1980; Stocker, 1976). This excludes from my account of friendship what Liz Spencer and Ray Pahl (2006) call 'useful contacts'. It includes, however, so-called 'confidants', 'comforters' and practical 'helpmates' who exchange emotional and/or practical support to each other over time, and whose bonds generally have both an instrumental and a non-instrumental character.

Note that by limiting my account of friendship to certain relationships I do not intend to imply that individuals should value these relationships more than others. Nor do I want to argue that theorists of justice should ignore interpersonal relationships, recognised by some as friendships, which my account here excludes. Both 'civic friendships' and 'useful contacts' can matter greatly for justice. ${ }^{3}$ However, I want to restrict my account of friendship in the way specified above for at least two reasons.

First, by excluding purely instrumental and non-affective ties, my account remains in line with most contemporary philosophers' understanding of 'personal friendship' (e.g. Blum, 1980; Goodin, 1985; Jollimore, 2001; Stocker, 1976). At the same time, by extending beyond purely altruistic and strongly intimate bonds, my account hopes to capture the multiform character of friendship, as well as the plurality of advantageproducing and equality-imperilling ties.

Second, relationships that exhibit an affective and non-instrumental component would seem to pose special resistance to political principles, more so than purely instrumental ties. Friendships, unlike useful contacts, are often regarded as paradigmatically 'personal' manifestations of individuals' identity and integrity. While granting that respect for equal liberty may set limits to the state's interference in all kinds of non-harmful interpersonal relationships, including purely instrumental ones, I will show how friendship, because of its affective and particularistic structure, poses particular resistance to principles of egalitarian justice. 
In the following section, I will show that both outcomes-centred and institutionalist theories of distributive justice have reasons to regard friendship as a political problem.

\section{How Friendship is Political}

Theorists of distributive justice contend that justice should be concerned primarily with distributive inequalities. For the purpose of this discussion I leave the metric of equality unspecified, as potentially including resources, opportunities, welfare or some combination of those. Theorists of distributive justice, according to what they take to be justice's primary subject, further divide into two categories: those who are primarily concerned with distributive outcomes versus those who are primarily concerned with the fairness of institutions. Both theories, taken up on their own terms, have reasons to be concerned with friendship.

Let us start with outcomes-centred theories. For some scholars, the ultimate subject of justice is the distributive upshot of goods and resources in society, regardless of whether it has been brought about by individual choices or institutions. G. A. Cohen (2008, p. 126), for example, writes that the fundamental concern of a theory of justice should be 'the pattern of benefits and burdens in society ... the upshot of structure and choices alike'.

In so far as egalitarians are concerned with outcomes resulting from institutions and private choices alike, they have prima facie reasons to be directly concerned with all individual choices that upset the distributive pattern by disadvantaging the worst off. These choices include those of whom to befriend and how to benefit one's own friends. These 'friendship choices', however well intentioned, have inegalitarian effects on the distribution of several benefits in society - inequalities that could be avoided if people were willing to make their friendship choices in a more equality-friendly way.

To illustrate, wealthy Sarah has many friends who are willing to baby-sit her children for no payment. Jessie, a poorer and isolated parent, must spend part of her already lower income on childcare because she lacks friends such as Sarah's. A state may offset the resulting increase in inequality of resources by, say, publicly subsidising childcare for poor single mothers. However, if people like Sarah's friends were motivated from the start to help poor rather than wealthy parents, or to pick their own friends according to an egalitarian ethos, the state could save the money spent on offsetting and redistribute it directly to the worst off. The overall upshot of institutions and private choices alike would then be more just if friendship choices were made according to equality principles.

That friendship affects distributive patterns becomes all the more evident once we consider the endless ways in which friendships can increase particular individuals' opportunities for advantage and welfare. As sociologists (e.g. Berkman, 1995; Lin, 2001) have demonstrated, friends, thanks to the practical and emotional support they provide, tend to increase measurably individuals' chances in life, ranging from their educational outcomes and labour market attainment to their resistance to diseases.

Friendship distributes chances of thriving unequally. It also does so in a way that reproduces existing inequalities, since individuals tend to befriend those who are similar to themselves (McPherson et al., 2001). Unless friends start choosing each other according to egalitarian principles, as long as some inequalities are in place, friendship is likely to function as a way of amplifying them. 
However, outcomes-centred theorists could argue that only those inequalities that reflect 'lucky and unlucky' circumstances, rather than individuals' chosen preferences and responsible choices, matter for justice (Cohen, 2008, p. 126). Since people choose and deserve their friends, it is not unfair that individuals' advantage is increased by their friendships.

Yet this argument is flawed. For often we are not responsible for other people's willingness or unwillingness to befriend us (Lazenby, 2010). Further, there are many factors beyond our control that fundamentally affect how many and what kind of friends we have - factors such as our innate sociability, our social class, gender and ethnicity (Adler et al., 1992), as well as the schools and clubs we attend, or the neighbourhoods in which we happen to grow up (Allan, 1996). The inequalities produced by friendship thus seem to satisfy, to a large extent, luck-based criteria.

It could however be objected that individuals also lack control over the outcome of roulette wheels, and yet few would deny that the differential outcomes resulting from engaging in deliberate roulette gambles count as option luck and need no equalisation (Dworkin, 2000, p. 73). The inequalities derived from friendships can only count as brute luck if we assume that the choice to befriend another person, unlike gambling, is 'necessitated' in some relevant sense, rather than purely optional.

Yet the choice to befriend other human beings is 'necessitated' in a sense in which gambling is not. First, a life without friendship would be for many a seriously diminished life, unlike a life without gambling. Second, because friendship confers important emotional and practical benefits, in a society where many people have friends, not to have friends can be, in and of itself, a disadvantage. Yet if the choice to befriend is 'necessitated' in a relevant sense, then the inequalities produced by friendship count, at least to a certain extent, as brute luck. They must thus fall under the purview of outcomes-centred egalitarians.

However, institutionalists reject the view that distributive outcomes are the primary concern of justice. They rather regard social institutions as being the primary target of justice-based evaluations. An unequal distribution counts as unjust only if it is due to an unfairness of 'the basic structure' - the major economic and political institutions of society (Rawls, 1971). Would institutionalists have any reason to be concerned with friendship? Certainly, friendship is not a major economic or political institution in any conventional sense. Yet so long as institutionalists include the family within the subject of justice, they have reasons to include friendship as well, for friendship shares many of the features that make the family, according to many, a legitimate subject of justice.

Susan Okin was among the first to argue that the family should be a subject of justice. She provides two main reasons to support this claim, which both rely heavily on empirical premises. Okin (1989, pp. 16-7) first argues that the family has pervasive effects on the aspirations and life prospects of its members, especially its most vulnerable ones. To cite an example, female children who grow up in a family where women are not considered equal to men are more likely to suffer a disadvantage when, say, they approach the job market. Yet there is empirical evidence (e.g. Harris, 1995; Rowe, 1995) that friendships also play a fundamental role in framing and shaping adolescents' aspirations for life. ${ }^{4}$ These studies claim that gender differences with regard to boys' and girls' sense of self and aspirations almost entirely result from peer-group socialisation. 
Yet if the friends we have are conditioned by the parents we have then perhaps theories of justice committed to substantive fair equality of opportunity should exclusively be concerned with the family. However, unless the nuclear family is abolished, something that many would consider as both unfeasible and undesirable, inequalities of opportunity due to family background will remain. Once we take the family as a given, the question of how inequalities of family background are reproduced - or rather reduced - through friendship only becomes all the more pressing.

Further, friendship formation is conditioned by factors other than family background. For example, empirical research (Moody, 2001) demonstrates that among adolescents coming from similar family backgrounds, some fail while others succeed in forming cross-class and cross-race friendships depending upon the socialisation policies adopted by their schools. Therefore, the effects of friendship on equality deserve to be considered at least in part independently of those of the family.

Okin (1989, pp. 17-8) argues that the family is a subject of justice for a second reason: it plays a crucial role in the moral development of future citizens. Within families, children interiorise values they will then bring, as adults, into the public sphere. Friendship may be said to meet this criterion as well. As psychologist Emily Buss (2000, p. 1233) argues, friendships are a fundamental aspect of adolescents' identity formation. Buss maintains that adolescents must have a diversified group of friends, in terms of socio-economic background, attitudes, gender and beliefs, if they are to develop those critical capacities necessary to assess and reject established social norms. By 'friends' Buss means trusted peers, with whom adolescents regularly spend time, share confidences and exchange emotional support (Buss, 2000, pp. 1270-2).

There are further, especially gender-related, issues that have preoccupied Okin and other feminists in the case of the family, which seem to concern friendship as well. For example, it is not uncommon for friends, especially female friends, to sacrifice justice entitlements in order to care for their needy friends (Rosenbury, 2007). This opens up the complex question of whether or not the benefits and recognition that feminists extend to carers within the family, for example mothers, ought also to be extended to friends who are carers. Whether this recognition would serve to mitigate or rather reproduce gender inequality is subject to disagreement (see Schwarzenbach, 2009). This and other important questions, which for reasons of space I cannot address here, show that exiling friendship from the realm of the political may result in neglecting inequalities that are as integral to distributive justice as the ones that have long preoccupied feminists in the case of the family.

In sum, institutionalists also have reasons to worry about friendship. However, when we ask how principles of justice should govern friendship, interesting problems arise.

\section{Choice Extensionism}

Outcomes-centred egalitarians tend to opt for choice extensionism (Cohen, 2008). They argue that principles of justice should directly govern private choices that produce relevant inequalities, and that could prevent such inequalities if made according to an egalitarian ethos. ${ }^{5}$ Friendship choices, I have argued, count among these choices.

In order to secure an egalitarian upshot, the choice extensionist can (1) require individuals to pick their friends according to equality-promoting principles, or (2) prohibit 
them tout court from distributing equality-imperilling benefits to their friends, or (3) require offset taxation on the benefits of friendship. Option (2) is ruled out, since the simple existence of a friendship necessarily produces advantage-increasing benefits (and burdens) for its parties, such as emotional support and social capital. Option (3) is also ruled out, for while we may arguably tax the material gifts of friendship, we cannot tax emotional support and social capital. Option (1) remains the only viable one. People should be required to act from an egalitarian ethos when forming their friendships.

However, requiring people to do so would compromise the very possibility of friendship. A person's action counts as an act of friendship, rather than as an act of, say, beneficence, only if he or she acts for the right reasons - as an expression of affection or concern for a particular person qua his or her friend, or as a response to his or her particular identity (Blum, 1980; Jollimore, 2001; Stocker, 1976). Friendship also requires that the particular moral identity of those involved in a relation of friendship be taken into account in deciding on right action. Since the egalitarian ethos would ask individuals to be motivated by, and act on, agent-neutral, equality-promoting reasons when befriending someone, their feelings or the particular identity of their friends would not be able directly to play a role or, at least, not a fundamental one, in determining their actions. This motivational gap between agent-relative reasons (and feelings) and egalitarian aims threatens the very possibility of friendship (Jollimore, 2001).

Now it could be argued that whereas feelings and particular identities must play a central role in sustaining already formed friendships, they need not play a role in the initiation of friendship. It would thus be perfectly compatible with friendship morally to require, say, wealthy individuals to provide poorer individuals with an initial opportunity to become their friends.

However, this solution, beyond sounding unacceptably patronising, fails for the following reason. If Alpha has a duty, as a matter of justice, to grant an opportunity to Beta to become her friend, Alpha would also have a duty to exit her friendship with Beta as soon as Beta becomes better off - and then to turn around and offer that same opportunity to someone less advantaged. This sequence clearly contravenes our understanding of friendship as a relationship among moral equals, developed over time and based upon trust. Therefore, choice extensionism would seem to be committed to the infelicitous conclusion that a just society is a society without friendship (a society in which friendships are replaced by purely instrumental relationships).

One way of solving this dilemma is to allow friends a prerogative to depart from the requirements of the egalitarian ethos (Cohen, 2008). However, if what primarily matters from the perspective of outcomes-based egalitarianism is the 'upshot of structure and choices alike', allowing this prerogative, as a matter of justice, may undermine the rationale and coherence of the entire egalitarian project (Estlund, 1998; Pogge, 2000).

According to Cohen, for example, the egalitarian ethos should apply to career choices - talented individuals should refrain from asking for economic incentives as a condition of choosing a productive job. Why should friendship choices, unlike talented individuals' career choices, be exempted from the demands of equality, if they both equally upset the egalitarian outcome? 
One option would be to argue that friendship choices, unlike career choices, are not selfish. However, if what primarily matters is the egalitarian upshot, we cannot easily succeed in differentiating selfish choices from non-selfish choices (Tan, 2004, p. 347). From the perspective of resulting outcomes, all choices that deliberately fail to contribute to the best state of affairs are somehow selfish.

Another option would be to point out that while economic choices are 'political' in a strong sense, friendship choices are so in a much weaker sense. While friendship choices seem simply to affect a given distributive pattern, economic choices also have the power to enhance/compromise the ability of political institutions to redistribute radically (Cohen, 2008, p. 365). However, friendship choices can also be political in the strong sense. To illustrate: within a society where people choose their friends (and thus distribute the advantages of friendship) according to an egalitarian ethos, incentives to, say, charitable giving - incentives aimed at promoting assistance to strangers - would be unnecessary and the money lost in tax exemptions could return to government, which could redistribute them directly to the worst off. Therefore, friendship choices seem to be as 'political' as market choices. It is thus unclear whether egalitarians could coherently grant a friendship-based prerogative to depart from equality.

Choice extensionists could then attempt to adopt a position similar to that of rule consequentialism in an effort to incorporate a space for friendship within the agent-neutral goal of justice. From the perspective of rule consequentialism, the agent-relative practice of friendship would be justified if it could serve to promote the agent-neutral aim (equality) better than any comparable practice. But this justificatory procedure is arguably impracticable, as we can imagine impartial agent-neutral practices of mutual beneficence that would realise egalitarian justice much better than friendships do. ${ }^{6}$

However, let us grant that the choice extensionist can somehow succeed in justifying a 'friendship prerogative'. If the prerogative is justified as a deviation from justice, then many would be left unsatisfied. If justice - as Cohen (2008, p. 7) defines it - is 'giving each person her due', it is not clear why we are deviating from 'our due' when spending time with, or assisting, our friends. Why should we not be entitled to a space of personal friendship as an integral part of what 'our due' is?

If instead we understand the friendship prerogative as being a requirement of justice itself, then we must answer the following question: how should a space for friendship partiality be factored into egalitarian principles for individuals?

\section{Friendship Satisfaction and Legitimate Partiality}

Cohen's treatment of market choices provides, by analogy, a possible answer to the question above. In relation to career choices, he argues that talented individuals have a prima facie duty to make these choices in a way that maximally benefits the worst off. However, Cohen adds that the egalitarian ethos would not require them to choose a career that they deeply dislike because their 'job satisfaction' should be factored into the egalitarian metric. It would contradict equality to demand that the talented choose a career path whose level of satisfaction is very low (Cohen, 2008, p. 184). We could thus extend this argument to friendship, by including a space for 'friendship satisfaction' in the egalitarian metric. 
Yet this strategy leads to unreasonable conclusions. In the case of productive choices, job satisfaction might (arguably) be defined in objective terms that apply equally to all, for example in terms of the number of work hours in proportion to salary, paid holidays and so on. Yet nothing like this is possible for 'friendship satisfaction' due to its particularistic character. For what counts as a satisfying friendship cannot be determined independently of the particular identity of those involved and of the relation itself.

Yet if we agree that 'friendship satisfaction' should be measured, at least in part, in accordance with the particular identity of each particular friendship, once friendship satisfaction is made part of the egalitarian metric we arrive at the result that individuals should be subject to differential burdens in promoting social equality, according to the particular identities of their friendships. For example, Alpha may be expected to do more than Beta in promoting equality, for the particular nature of Alpha's friendship leaves her with more friendship-free time than Beta has. But many would reject as unreasonable a conception of justice that makes the allocation of social burdens heavily dependent upon the particular identity of individuals' interpersonal relationships.

We may try to solve this problem by developing a theory that objectively establishes the boundaries of legitimate friendship partiality - how much time and resources friends can legitimately dedicate to their friends - equally for all. For example, some scholars argue that it is possible to determine impartially the legitimate boundaries of parental partiality - what parents can legitimately give to their children - by first defining, from an impersonal point of view, the distinctive goods that the parent-child relation is meant to realise (Brighouse and Swift, 2009). A level of parental partiality necessary to promote distinctive familial goods is permitted; partiality beyond this threshold is not. The same strategy could be applied to the case of friendship. Only actions necessary to fulfil the distinctive goods of friendship would be permitted and friendship satisfaction would be measured accordingly.

However, this strategy is problematic. First, there is irreducible disagreement about the precise list of goods that particular human relations, including the family, should realise. Regardless, even if we grant that this view could successfully work in the case of the family, it may not work in the case of friendship. This is because the 'good' that parents are meant to realise may be regarded as being fixed, at least partly, by their social role, quite independently from the parents' particular identities (Hannan and Vernon, 2008). By contrast, the 'good' that friends are meant to realise seems to be more dependent on the particular identities of friends. This point is made by Michael Hardimon (1994, p. 336): 'Familial roles ... being institutionally defined, are genuine institutional roles ... Friendship, however, is not an institution ... What counts as a friendship is up to the parties in a way in which what counts as a family ... is not'. Hardimon may be guilty of obscuring the many similarities between the family and friendship. Yet the claim that what counts as the good of each and every friendship is up to friends to decide more than what counts as the good of each and every parent-child relation (or doctor-patient relation) sounds plausible. To illustrate, If Jon was little Tom's father, we could object that Jon sending sporadic letters to Tom is insufficient to realise the good of parenthood - a good whose content can be largely specified in relation to the developmental roles of parents, quite independently of the identity of Jon. By contrast, if Jon was Tom's friend, it could be perfectly reasonable for Jon to conduct his friendship in that way. This is 
because the good of Jon and Tom's friendship is largely determined by the parties themselves.

Yet if we cannot fix the boundaries of legitimate friendship partiality equally for all, we cannot carve out a space for friendship partiality within the egalitarian ethos without falling back into an unreasonable conception of justice that allocates social burdens according to the particular identity of each individual's friendships. Therefore, choice extensionism fails as a mode of applying justice to friendship. I turn now to legal extensionism.

\section{Legal Extensionism}

It might be argued that just as principles of justice apply to the institutional structure of the family, so ought they equally to apply to the institution of friendship. However, if we conceive of an institution as a legal system of rules, as institutionalists generally do, it is unclear how principles of justice could extend to friendship in this way. There is no 'friendship law' equivalent to family law. It is true that long-lasting friendships, which produce dependencies among individuals, may generate enforceable legal obligations (Rosenbury, 2007). Yet friendship lacks a formalised legal structure. Most importantly, as some have argued, part of what makes friendship a distinctive realm of freedom is precisely the non-legally obligatory character of friendly actions, as well as its non-institutional nature (see Blatterer, 2013). A framework of rules that precisely defines the offices of friends with their rights and duties, powers and immunities may thus be resisted as threatening the distinctiveness of friendship.

Perhaps then principles of justice should at most indirectly shape and constrain what friends can distribute to each other, through the economic and legal institutions of the basic social structure (Rawls, 1993, pp. 266-7) - for example by banning cronyism in hiring practices and taxing the material gifts of friendship.

Yet those committed to substantive fair equality of opportunity would find the insistence on anti-discrimination policies and redistributive taxation insufficient to reconcile friendship partiality and equality. Anti-discrimination policies are insufficient because they ignore the many background factors, including affective relationships, that shape individuals' talents and motivations. Gift taxation is insufficient to secure fair equality of opportunity because friendships unavoidably and legitimately distribute immaterial goods cultural and social capital - which, like material gifts, produce advantages but which, unlike material gifts, cannot be taxed and transferred.

Governments may try and compensate, ex post, for the inegalitarian distribution of immaterial gifts through welfare programmes. But it is difficult to design programmes that can compensate for the large inequalities of benefits that friendships provide, and to do so without being excessively intrusive. Also, these kinds of ex post solutions would do little, if nothing, to prevent ex ante the very patterns of socialisation through which relevant inequalities first arise. If instituting a complete public framework of friendship law is undesirable, indirect solutions for adjustment seem insufficient.

\section{The Relational Distributive Structure}

I wish to argue that principles of justice should apply, ex ante, to the structure of those organisations (the identity of which needs to be specified) that fundamentally affect how 
people form friendships and what kind of friendships they form. I will call this set of organisations, regarded as a whole, the relational distributive structure. The term 'relational' refers to the fact that the object that is produced and distributed by the set of organisations in question is constituted by relationships, or opportunities for relationships, rather than, say, economic resources or job opportunities. The term 'structure', despite its monolithic connotation, refers to a multiform plurality of organisations tied together by this common distributive, but relational, function. ${ }^{7}$ Just as the economic institutions of Rawls' basic structure control the production and distribution of economic resources across society, similarly, different types of social organisation, taken together, fundamentally shape the distribution of relational resources.

Before examining further the nature and shape of the relational distributive structure, let me clarify why principles of justice should apply to it. ${ }^{8}$ If one could achieve a more egalitarian 'production and distribution' of friendships and opportunities for friendship formation ex ante, this would prevent, rather than repair, the inegalitarian consequences of friendship, while leaving individuals (within certain constraints) free to act according to the distinct particularities of their friendships once formed. ${ }^{9}$ Although still partial, this would be the best reconciliation of justice and friendship partiality.

As previously argued, both the principle of fair equality of opportunity and the requirements of democratic citizenship point toward structuring the practices of friendship formation, so as to (1) facilitate the formation of friendships that (a) mitigate rather than reproduce pre-existing (family-based) inequalities of socio-economic status, and (b) foster the development of free and equal citizens. These are friendships based on difference (across dimensions of class, race, gender, beliefs and so forth) rather than sameness to self. At the same time, they are relationships within which friends regard and respect each other as moral equals.

Further, whereas the fact that some people are significantly better off compared to similarly placed individuals as a result of their friendships is not per se an injustice - people may prefer isolation to socialisation - it seems, nevertheless, unfair if some people are so advantaged over others as a consequence of social norms and institutions. ${ }^{10}$ In particular, judgements of unfairness, and even injustice, become sound when we start regarding the inequalities of advantage produced by friendships as resulting from a failure of those institutions that directly affect, and to some extent, control the formation of interpersonal relationships across society. Therefore, if something like a relational distributive structure can be located, it should, as a matter of justice, be designed so as to (2) prevent large inequalities of opportunities to form and to cultivate friendships that satisfy conditions (a) and (b) above.

Yet most philosophers tend to regard friendships as spontaneous acts of free will. Interpersonal relationships are not 'produced and distributed' social resources, as economic resources are. Rather, individuals spontaneously develop them. Against this view, I contend that friendships, and the opportunities to access them, must in many respects be regarded as socially distributed resources. They have clear social bases, and it is these social bases that should be the direct subject of justice. Yet in order to speak appropriately of a relational distributive structure, we must be able to locate a set of formal or informal institutions that directly affect the production and distribution of friendships across society. 
By 'directly affect' I mean that how people form friendship ties and what kind of ties they form depends fundamentally on these institutions, and that these institutions have, to some extent, control over the process of friendship formation.

Recent sociological research (e.g. Moody, 2001; Small, 2009) has shown that the ways in which certain institutions and organisations are structured, as well as the norms of socialisation they foster, affect fundamentally whether people form friendships, as well as the kinds of friendships they form.

As one sociologist (Small, 2009, p. 5) explains:

people's social capital depends fundamentally on the organizations in which they participate routinely ... through multiple mechanisms, organisations can create and reproduce network advantages in ways their members may not expect or even have to work for. ... organizational contexts affect most aspects of social capital, including whether a person makes ties, what kind of ties she makes, whether the goods in those ties are available to the person, and how those goods are acquired.

Now if it is true that some institutions have this power, then the claim that there is a relational distributive structure starts to sound more plausible. This structure is made up of those 'organizational contexts [that] affect most aspects of social capital'. But what institutions constitute this structure? The response to this question is complex and certainly contextual in nature. Yet we can try to acquire a clearer idea of what organisations matter for friendship formation, by first understanding why and how organisations matter.

It is often argued that the following factors count as especially relevant in affecting the production of affective ties and interpersonal trust: agents form affective ties when they have (1) the opportunity to interact informally; (2) the opportunity to interact repeatedly, frequently and for a sustained amount of time; (3) a common purpose or project or interest connected to their interaction; and (4) the opportunity to interact in conditions of cooperation rather than pure competition. ${ }^{11}$

Now in Western contemporary societies these factors are under the control of those organisations in which adolescents and adults routinely participate. These organisations include educational institutions, workplaces, voluntary associations and also organised spaces such as neighbourhoods. These organisations can structure their own norms in a way that fosters the conditions under which friendships are formed, potentially reducing the justice-imperilling effects of friendship (Small, 2009). By providing people from different socio-economic backgrounds with opportunities for them to socialise and to form affective bonds, organisations can generate a redistribution of social capital.

To illustrate: James Moody's (2001) research on friendship segregation shows that the way students are assigned to academic tracks, the way in which they are mixed within grades, the way admission policies to extra-curricular activities (e.g. sports clubs) are designed, and even the teaching methods adopted by their teachers, are determinants of how many and what kind of friends students have. He concludes that 'while friendship segregation is a common outcome in racially heterogeneous schools, it need not be. The ways that schools organise student mixing has a strong effect on interracial friendship patterns' (Moody, 2001, p. 682). Subsequent studies (Grewal et al., 2012) at Stanford University have shown that friendship integration in schools has noticeable effects on the 
educational achievements (and thus the future opportunities) of adolescents with low economic status. They demonstrate, for example, that, other things being equal, students with low economic status tend to obtain better educational outcomes, conditional on their own attributes, if they develop trust-based bonds with peers who have higher economic status.

Although the relationship between social capital and social inequality remains ambiguous (Pahl, 2000, pp. 158-60), these and similar studies show that, by appropriately designing their membership policies and internal structure, civil society organisations can create opportunities for integrated friendships and that this, in turn, has a positive impact on pre-existing inequalities. Surely, in order for friendship opportunities to be accessible, it is also important that individuals secure the material and temporal autonomy necessary to participate in these organisations in the first place. However, it is worth emphasising that, other things being equal in economic terms, individuals may still enjoy very different opportunities for friendship formation, depending upon the ways in which the accessibility and internal structure of common places of interaction are organised.

To apply principles of justice to the relational distributive structure therefore means to shape the structure of civil society, including urban spaces, so as to foster the formation of cross-cutting membership organisations, the promotion of non-hierarchical and participatory structures within these organisations, and the furtherance of policies of diversity and socialisation.

The question remains of on which moral grounds civil organisations should be expected to endorse this social responsibility. Further, what can government do to 'distribute' friendships in a more egalitarian way?

\section{Policy Implications}

The fact that civil society organisations can play an essential role in fulfilling the demands of equality does not mean that they should. The entitlement of organisations, whether they be churches, service-providing associations, clubs or neighbourhoods, to be exclusive and perhaps even hierarchical - it could be argued - is similar to the prerogative of individual friends to choose the friends they want and conduct their friendships as they choose. If principles of justice cannot directly regulate the choices of friends why should they regulate the choices (policies and internal structure) of civil society organisations? Two things need to be said in response to this.

First, although the principle of organisational autonomy is a fundamental aspect of freedom of association, as Stuart White (1997) argues, and as is recognised by many legal systems, the strength of this principle decreases in proportion to the instrumentality and public role of associations, while increasing in proportion to their expressivity. Many civil society organisations have a less expressive character than others. Service-provider organisations, like childcare centres, are less expressive than churches, and neighbourhoods are less expressive (if expressive at all) than friendships.

The principle of organisational autonomy is even weaker for those organisations that have a clear public character (public schools or public universities) and also for those organisations, the majority in many democracies, which even if formally private are under receipt of state funding and contracts. Demanding that these organisations change their 
organisational norms or introduce specific policies so as to foster patterns of socialisation that satisfy justice principles would then sound much more reasonable than asking individuals to pick their friends in specific ways.

Second, there is a more fundamental argument, based on the normative distinctiveness of civil society as a social sphere, to be made in favour of the inclusiveness of civil society organisations. Civil society organisations, by definition, are neither personal nor political, but rather civil institutions. As Alexis De Tocqueville (1990 [1835]) argued, civility mediates between the pure individualism of personal relations and political virtues. I would argue that one way for civil society to fulfil what makes it distinctive as a public-private mediator, in relation to social justice, is to accept the burden of reconciling the 'political' demands of equality with the 'personal' demands of friendship. Civil society organisations can do this by shaping patterns of socialisation in a way that (roughly) equalises, ex ante, the opportunities to form integrated friendships which compensate for, rather than enhance, pre-existing inequalities.

However, to say that principles of justice should apply to the organisations that form the relational distributive structure is not to say that these organisations ought to be coerced to produce and distribute friendships in a more egalitarian way. In this respect, my proposal is compatible with granting basic liberties priority over equality. In order to promote the requirements of egalitarian justice while respecting the constraints set by individuals' liberties - for example the demands of freedom of association - it can be argued that soft means, like incentives, rather than coercion, should be used to encourage civil society organisations to adopt policies that tend to 'equalise' opportunities for friendship advantages.

This has an important implication for tax-incentive structures. Government, when directing tax incentives to civil society organisations, should not simply look the material goods that associations allocate or provide (education, childcare, etc.) but also at the type of relations (friendship integration vs. segregation) these associations foster. For example, inclusive coalition membership groups, or organisations that adopt specific policies of socialisation, should be given priority in the incentive scheme over more exclusive (e.g. religious) groups, even if they distribute the same services to the public. Elitist clubs might not be tax-exempted at all. Understanding the role of civil society as a relational distributive structure, and as a mediator between the political and the personal, gives to government an important justification for restructuring civil society according to principles of justice.

It is also worth noting that while it would contravene the value of friendship to provide individuals with a legally sanctioned recipe for how to conduct their friendships, restructuring ex ante the social norms that drive friendship formation according to principles of justice would not contravene the value of friendship. For these norms do not dictate specific reasons for action. Neither do they fix, once and for all, the rights and duties of each and every friend. They rather establish the 'background conditions' of friendship formation against which this reasoning can freely take place, in the same way as economic institutions establish the background conditions against which economic transactions can take place.

The enterprise of shaping the background conditions of friendship may still appear to some as an unacceptable form of social engineering. However, no human action, including friendship, takes place in a vacuum. There will always be a social structure in place that 
determines which default sets of options are available to individual choices, including friendship choices. Changing the structure of an option set, without coercively restricting any choice or action, does not necessarily amount to restriction of freedom, at least so long as people maintain the choice to opt out of undesirable arrangements (Thaler and Sunstein, 2008).

The important question is about what kind of engineering is justified in light of public values, compatible with individual liberty. I am not arguing that choice architects should reshape individuals' default option sets so as to make their lives longer and better. I rather argue that a state has justice-based reasons to structure default options for friendship formation. Friendships should be regarded as productive resources - a form of social capital - which like economic capital can significantly increase individuals' advantage across several dimensions. Once we accept this parallelism, we should also accept the idea that the policies required for the distribution of relational opportunities to be more equal from the start is no less justified than the policies required for the distribution of economic resources to be more equal.

We must then deal, case by case, with the question of which of the many available ways of structuring default options constitute illegitimate violations of basic liberties and which do not. This is, however, a question that applies to all cases, thousands in our ethical life, where egalitarian justice and liberty conflict.

Although drawing a precise line between legitimate and illegitimate forms of social engineering would demand a separate treatment, I want to illustrate with some examples the difference between, on the one hand, changing the default options available for friendship formation and, on the other hand, coercing people into doing certain things that conflict directly with their already formed beliefs and aspirations. To illustrate: in a society like the US, socio-economic segregation by school is a common cause of friendship segregation. To tackle friendship segregation, we may resist forcing parents to send their children to schools in deprived areas against their will. However, governments should actively prevent segregation by neighbourhood in the first place, by adopting rent-control policies, banning zoning laws and funding the construction of public recreational spaces within wealthy neighbourhoods. In this way, the default option available to parents' school choice would be one that is compatible with the requirements of friendship integration parents would need to try much harder to shield their children from what they perceive to be the dangers of integration. Schools themselves should then design their internal tracking system, as well as their extra-curricular activities, with the direct aim of promoting friendship integration. Through schools, government should provide special financial and organisational aid for those leisure activities out of school - for example summer camps that are crucial for adolescents' friendship formation but are often outside the reach of low-income families. These activities do not seem to impose any direct constraint on individuals' freedom of association.

Similarly, in order to encourage cross-class, cross-racial and cross-gender bonds among adults, it would (arguably) be unacceptable for a government to force citizens to volunteer or participate in specific membership associations. However, it seems acceptable for a government to design charitable deductions with the aim of friendship integration in mind. For example, a government can decide to make charitable deductions conditional on actual 
participation in associations that have an inclusive membership, while withdrawing deductions from donations directed to organisations that are exclusive or elitist in nature (e.g. so-called 'old boy networks'). Since individuals have no pre-institutional entitlement to charitable deductions (Reich, 2010), it is within the legitimate scope of governments to decide, in light of justice principles, what public purposes these deductions should serve.

\section{Conclusion}

The goal of this article has been to show how theories of justice should go about addressing the inequalities produced by personal friendship. In considering the problematic tension between friendship and equality, I have argued that theorists of justice should move away from their exclusive focus on individual personal choices and legal institutions, and consider a different, often neglected unit: relational social structures. They should also consider the opportunities to form friendships as a legitimate object of distribution.

\section{(Accepted: 10 October 2013)}

\section{About the Author}

Chiara Cordelli is a Lecturer in Political Theory at the University of Exeter, UK. Before joining Exeter, she was a postdoctoral scholar at the Stanford Center on Philanthropy and Civil Society and a Visiting Scholar at the Center for Advanced Study in the Behavioral Sciences at Stanford University. Her main research interests focus on theories of distributive justice, theories of civil society and the distinction/relation between the personal and the political. Her work has appeared in the Journal of Political Philosophy and the Critical Review of International Social and Political Philosophy. Chiara Cordelli, Department of Politics, University of Exeter, Amory Building, Rennes Drive, Exeter EX4 4RJ, UK; email: c.cordelli@exeter.ac.uk

\section{Notes}

I wish to thank Sam Arnold, Will Braynen, Mark Budolfson, Eamonn Callan, Tom Dougherty, Matthias Freidank, Sarah Hannan, Hyunseop Kim, Rob Jubb, Hugh Lazenby, Jonathan Levy, Joe Mazor, Woody Powell, Rob Reich, Debra Satz and three anonymous reviewers for providing very helpful comments on early versions of this article. Previous versions were presented at the Library of Congress in Washington DC, at the Political Theory Workshop at University College London and at the Political Theory Seminar at Stanford University. I thank the participants of these seminars for their comments and suggestions. I also thank the Stanford Center on Philanthropy and Civil Society for its institutional support.

1 Political theorists have mostly looked at friendship as a political idea worthy of promotion because it is necessary to support democratic values. I will, by contrast, look at friendship as a personal relationship that poses a specific threat to distributive justice.

2 This, however, is not to say that spouses cannot also be friends.

3 On the one hand, civic friendship may be a necessary precondition of social justice (Allen, 2004; Schwarzenbach, 2009, p. 55). On the other hand, useful contacts can generate relevant advantage, for example by working as privileged vehicles for novel information (Granovetter, 1973). However, these ties arguably produce less of the benefits, in particular emotional and practical support, that stronger ties produce and that greatly affect people's health, educational outcomes and even labour market attainment (Pahl, 2000, pp. 46-51).

4 Arguably young children lack some of the capacities necessary to have friendships - for example the ability to reciprocate - but most adolescents possess them (Pahl, 2000, p. 100).

5 By 'egalitarian ethos' I mean a motivational force that pushes individuals to act on egalitarian principles.

6 The practice of mutual beneficence may not better realise justice if we assume that each person has a justice-based equal claim to the goods of friendship. However, we seem to have special reasons to be partial towards our friends, simply in virtue of our special relationship with them and quite independently of distributive considerations.

7 By using the term 'structure' I do not mean to obscure the multidimensional and complex nature of the contexts of friendship formation (Adams and Allan, 1998). I simply want to suggest a parallelism between the Rawlsian 'basic structure' and those institutions that fundamentally affect the production and distribution of relational resources. Both these sets of institutions, in my view, ought to be regarded as subjects of justice.

8 For a more extensive treatment of 'the relational distributive structure' as a primary subject of justice, see Cordelli, forthcoming.

9 To be clear, I am not arguing that 'equalising' friendships would eliminate social inequalities. This is because friendship is only one vehicle through which social inequalities are reproduced.

10 I leave aside the issue of whether friendship inequalities due to lack of genetic talents count as unjust.

11 For a review of the sociological literature on how and why these factors matter, see Small, 2009, ch.1. 


\section{References}

Adams, R. and Allan, G. (1998) Placing Friendship in Context. Cambridge: Cambridge University Press.

Adler, P., Kless, S. and Adler, P. (1992) 'Socialization to Gender Roles', Sociology of Education, 65 (3), 169-87.

Allan, G. (1996) Kinship and Friendship in Modern Britain. Oxford: Oxford University Press.

Allen, D. (2004) Talking to Strangers: Anxieties of Citizenship since Brown v. Board of Education. Chicago IL: University of Chicago Press.

Berkman, L. (1995) 'The Role of Social Relations in Health Promotion', Psychosomatic Medicine, 57 (3), $245-54$.

Blatterer, H. (2013) 'Friendship's Freedom and Gendered Limits', European Journal of Social Theory, 16 (4), $435-56$.

Blum, L. (1980) Friendship, Altruism and Morality. Boston MA: Routledge \& Kegan Paul.

Brighouse, H. and Swift, A. (2009) 'Legitimate Parental Partiality', Philosophy and Public Affairs, 37 (1), 43-80.

Buss, E. (2000) 'The Adolescent's Stake in the Allocation of Educational Control between Parent and State', University of Chicago Law Review, 67, 1233.

Cohen, G. A. (2008) Rescuing Justice and Equality. Cambridge MA: Harvard University Press.

Cordelli, C. (forthcoming) 'Justice as Fairness and Relational Resources', Journal of Political Philosophy.

De Tocqueville, A. (1990 [1835]) Democracy in America, ed. P. Bradley. New York: Random House.

Devere, H. and Smith, G. (2010) 'Friendship and Politics', Political Studies Review, 8 (3), 341-56.

Dworkin, R. (2000) Sovereign Virtue. Cambridge MA: Harvard University Press.

Estlund, D. (1998) 'Debate: Liberalism, Equality, and Fraternity in Cohen's Critique of Rawls', Journal of Political Philosophy, $6(1), 99-112$.

Goodin, R. (1985) Protecting the Vulnerable. Chicago IL: University of Chicago Press.

Granovetter, M. (1973) 'The Strength of Weak Ties: A Network Theory', Sociological Theory, 1 (6), 201-33.

Grewal, E. T., Mo, C. H., Williams, B and Nie, N. (2012) 'With a Little Help from Our Friends: Peer Effects on Educational Attainment'. Paper presented at the Annual Meeting of the American Education Research Association, 25 June. Available from: http://www.stanford.edu/ etgrewal/Grewaletal_SES_Attainment_2012 [Accessed 8 July 2013].

Hannan, S. and Vernon, R. (2008) 'Parental Rights: A Role-Based Approach', Theory and Research in Education, 6 (2), 173-89.

Hardimon, M. (1994) 'Role Obligations', Journal of Philosophy, 91 (7), 333-63.

Harris, J. (1995) 'Where is the Child's Environment?', Psychological Review, 102 (3), 458-89.

Hooker, B. and Little, M. (2000) Moral Particularism. Oxford: Clarendon Press.

Jollimore, T. (2001) Friendship and Agent Relative Morality. New York: Studies in Ethics.

Lazenby, H. (2010) 'One Kiss Too Many? Giving, Luck-Egalitarianism and Other-Affecting Choice', Journal of Political Philosophy, 18 (3), 271-86.

Lin, N. (2001) Social Capital: A Theory of Social Structure and Action. New York: Cambridge University Press.

McPherson, M., Smith-Lovin, L. and Cook, J. (2001) 'Birds of a Feather: Homophily in Social Networks', Annual Review of Sociology, 27, 415-44.

Moody, J. (2001) 'Race, School Integration, and Friendship Segregation in America', American Journal of Sociology, 107 (3), 679-716.

Okin, S. (1989) Justice, Gender, and the Family. New York: Basic Books.

Pahl, R. (2000) On Friendship. Cambridge: Polity Press.

Pogge, T. (2000) 'On the Site of Distributive Justice: Reflections on Cohen and Murphy', Philosophy and Public Affairs, 29 (2), 137-69.

Rawls, J. (1971) A Theory of Justice. Cambridge MA: Harvard University Press.

Rawls, J. (1993) Political Liberalism. New York: Columbia University Press.

Reich, R. (2010) 'Toward a Political Theory of Philanthropy', in P. Illingworth, T. Pogge and L. Wenar (eds), Giving Well: The Ethics of Philanthropy. Oxford: Oxford University Press, pp. 177-95.

Rosenbury, L. (2007) 'Friends with Benefits?', Michigan Law Review, 106 (2), 189-242.

Rowe, R. (1995) The Limits of Family Influence: Genes, Experience, and Behavior. New York: Guilford Press.

Schwarzenbach, S. (2009) On Civic Friendship: Including Women in the State. New York: Columbia University Press.

Small, M. (2009) Unanticipated Gains: Origins of Network Inequality in Everyday Life. New York: Oxford University Press.

Spencer, L. and Pahl, R. (2006) Rethinking Friendship: Hidden Solidarities Today. Princeton NJ: Princeton University Press.

Stocker, M. (1976) 'The Schizophrenia of Modern Ethical Theories', Journal of Philosophy, 73 (14), 543-66.

Tan, K.-C. (2004) 'Justice and Personal Pursuits', Journal of Philosophy, 7 (7), 331-62.

Thaler, R. and Sunstein, C. R. (2008) Nudge: Improving Decisions about Health, Wealth, and Happiness. New Haven CT: Yale University Press.

White, S. (1997) 'Freedom of Association and the Right to Exclude', Journal of Political Philosophy, 5 (4), $373-91$. 